\title{
The improvement of composite plates' indicators from cotton and flax spinning waste by modification of raw materials
}

\author{
Alexander Ibragimov ${ }^{1}$, Tatyana Vakhnina $^{2}$ and Irina Susoeva ${ }^{2^{*}}$ \\ ${ }^{1}$ Moscow State University of Civil Engineering, Yaroslavskoe shosse, 26, Moscow, 129337, Russia \\ ${ }^{2}$ Kostroma state university, 156005, Kostroma, Russia
}

\begin{abstract}
The article is devoted to solve the problem of modification of the non-returnable cotton and flax spinning waste in order to improve the physical and mechanical characteristics of composite heat-insulating plates based on these wastes. The modification of the vegetable filler with a $1 \%$ solution of sulfuric acid made it possible to increase the physical and mechanical indicators of plates. The thermal insulation properties of the composite plate material with some soft acid modification of the filler did not change significantly.
\end{abstract}

\section{Introduction}

Recycling including vegetable is one of the directions in resource-saving technologies. Annual wastes are used for the production of composite materials, as well as for construction. There is an experience of using bonfires, straw as filler for manufacturing of heat-insulating plate materials $[1,2,3]$. Secondary waste spinning manufactures unlike other vegetable materials are not used for the production of construction materials, although this raw material is characterized by a number of valuable technical properties. Pulverized non-returnable waste from vegetable fiber spinning can be used for the production of heat insulation plates if necessary operational properties are provided [4].

If other types of return flax and cotton fiber waste are used, then non-returnable wastes are disposed of by incineration or landfill. The solution of recycling management will lead to an improvement in the environmental situation.

The properties of non-returnable pulverized spinning wastes are mostly determined by the fiber structure, physical properties, susceptibility to chemical influences. The reason for the insufficient strength of composites from pulverized wastes is the poor adhesion of the binder to the filler particles. This is due to the presence of fatty substances on the surface of the particles of flax and cotton.

To improve the strength of the composite plate material which is based on pulverized waste of flax and cotton, surface modification of cotton fibers can be used. Fiber modification can be carried out by physical or chemical methods [5, 6], by UF-radiation [7]. According Fras Zemljič L. an effective method of increasing strength, wet ability,

\footnotetext{
*Corresponding author: i.susoeva@yandex.ru
} 
adsorption capacity is the treatment with weak acid solutions [8]. According to many researchers, the most common methods of modifying vegetable fibers are alkaline or acid hydrolysis [9 - 14].

\section{Materials and Methods}

The samples of composite plate material from non-returnable waste of flax fiber production were manufactured in the laboratory of the department of LDP KSU. 1\% sulfuric acid solution $\mathrm{H}_{2} \mathrm{SO}_{4}$ was used for modification. Urea formaldehyde binder (UF), phenol formaldehyde binder (PF), liquid glass $-\mathrm{Na}_{2} \mathrm{O}\left(\mathrm{SiO}_{2}\right) \mathrm{n}$ and alumochromosphate binder $\mathrm{CrAl}_{3}\left(\mathrm{H}_{2} \mathrm{PO}_{4}\right) \mathrm{n}$ were used as binders for composite materials. $\mathrm{NH}_{4} \mathrm{Cl}$ was used as a curing agent for UF . Samples plate materials were made by wet production method by pressing and drying at $100^{\circ} \mathrm{C}$. The average density of the plates was $375 \mathrm{~kg} / \mathrm{m}^{3}$, the consumption of binders was $30 \%$ by weight of the amount of filler. For the produced samples of plates, the following was determined: ultimate strength at static bending, $\mathrm{MPa}$; density, $\mathrm{kg} / \mathrm{m}^{3}$; swelling thickness for 24 hours, \%; water absorption for 24 hours, $\%$, coefficient of thermal conductivity, $\mathrm{W} /(\mathrm{m} \cdot \mathrm{K})$.

\section{Experimental part}

The composition of different batches of thermal insulation materials is presented in Table 1 . The results of determining the physical and mechanical properties of composite materials are presented in Table 2 .

Table 1. Composition of heat-insulating materials.

\begin{tabular}{|c|c|c|c|}
\hline Batch of composites & Binder & Precipitator & Hardener \\
\hline 1 & PF & $\mathrm{Al}_{2}\left(\mathrm{SO}_{4}\right)_{3}$ & - \\
\hline 2 & UF & - & $\mathrm{NH}_{4} \mathrm{Cl}$ \\
\hline 3 & Sodium silicate & $\mathrm{Al}_{2}\left(\mathrm{SO}_{4}\right)_{3}$ & - \\
\hline 4 & Alumochromophosphate & $\mathrm{Al}_{2}\left(\mathrm{SO}_{4}\right)_{3}$ & - \\
\hline
\end{tabular}

The coefficient of thermal conductivity of composites is in the range from 0.089 to $0.091 \mathrm{~W}$ $/(\mathrm{m} \cdot \mathrm{K})$ for materials based on cotton filler, from 0.058 to $0.059 \mathrm{~W} /(\mathrm{m} \cdot \mathrm{K})$ for materials from flax waste, both for plates from modified raw materials and for control panels without modification.

Table 2. Results of definition of physicomechanical properties* plates.

\begin{tabular}{|c|c|c|c|c|}
\hline $\begin{array}{l}\text { Batch of } \\
\text { composites }\end{array}$ & $\begin{array}{l}\text { Bending } \\
\text { strength } \sigma, \mathrm{MPa}\end{array}$ & $\begin{array}{l}\text { Thicknes } \\
\text { swellings, } \mathrm{Ph}, \%\end{array}$ & $\begin{array}{l}\text { Water absorption, } \\
\mathrm{W}, \%\end{array}$ & $\begin{array}{l}\text { Density, } \rho, \\
\mathrm{kg} / \mathrm{m}^{3}\end{array}$ \\
\hline 1 & $0.50 / 0.56$ & $3.65 / 3.23$ & $200 / 120$ & $326 / 327$ \\
\hline 2 & $0.18 / 0.21$ & $2.01 / 1.85$ & $205 / 145$ & $321 / 324$ \\
\hline 3 & $0.62 / 0.63$ & $5.68 / 5.16$ & $199 / 132$ & $325 / 327$ \\
\hline 4 & $0.59 / 0.61$ & $3.07 / 2.72$ & $150 / 125$ & $416 / 419$ \\
\hline
\end{tabular}




\begin{tabular}{|c|c|c|c|c|}
\hline \multicolumn{5}{|c|}{ Control (without modification) } \\
\hline 1 & $0.09 / 0.31$ & $8.36 / 7.54$ & $244 / 179$ & $344 / 347$ \\
\hline 2 & $0.26 / 0.48$ & $7.33 / 5.76$ & $234 / 138$ & $348 / 352$ \\
\hline 3 & $0.21 / 0.41$ & $5.98 / 5.81$ & $239 / 142$ & $350 / 353$ \\
\hline 4 & $0.36 / 0.46$ & $5.97 / 5.80$ & $235 / 141$ & $352 / 355$ \\
\hline
\end{tabular}

* Above the dash for slabs of cotton, under the slab for flax plates.

\section{Conclusions}

The improvement of physical and mechanical indicators of plates (with the exception of plates on UF) with mild acid modification of vegetable filler is explained by two reasons. Firstly, the removal of a part of the fatty substances from the filler surface with a weak solution of sulfuric acid. Secondly, when the hydrolytic action is soft on the surface of the vegetable filler, a mixture of the initial cellulose and the insoluble products of its initial hydrolysis is obtained [15]. The degree of polymerization of cellulose decreases, some of its amorphous regions are removed, and the groups bound in the original cellulose are activated. This creates new hydrogen bonds between the cellulose chains, as well as chemical bonds with the active groupings of the matrix-binder.

When using an acid-modified vegetable filler and UF with an acid hardener, the binder is prematurely cured prior to the pre-pressing and drying step. This reduces the physical and mechanical properties of the plates.

As the density of the material does not change significantly, the coefficient of thermal conductivity also does not have significant fluctuations when soft acid modification of the filler of plates is used.

The results of the experimental research showed that plates based on a modified filler made from pulverized waste products of flax and cotton spinning industries have a strength under static bending of more than $0.4 \mathrm{MPa}$, that is, they meet the requirements of standard documentation - state standard 4598-86 to the analogue material - wood fiber boards wet mode of production.

Acid modification increases the strength of plates, the exception is the use as a binder UF. To a greater extent, the effect of increasing strength affects when cotton waste is used as a filler.

The best-strength results for this method of modifying the filler material from the nonreturnable waste products of both cotton and flax fibres are obtained when inorganic binders as a matrix are used, while the water resistance of the material is higher when aluminochromophosphates are used.

\section{References}

1. J. Zhu, Materials. 6, 5171-5198 (2013) DOI:10.3390/ma6115171

2. I. Peroni, International Journal of Materials and Product Technology. 36, 396-416 (2009)

3. H. P. S. A. Khalil, M. A. Tehrani, Y. Davoudpour, A. H. Bhat, M. Jawaid, A. Hassan, Journal of Rein forced Plastics and Composites. 32(5), 330-356 (2013) DOI: $10.1177 / 0731684412458553$ 
4. I.V. Susoeva, T.N. Vahnina, A.A. Titunin, J.A. Asatkina, Magazine of Civil Engineering. 3(71), 39-50 (2017) DOI: 10.18720/MCE.71.5

5. B. He, J. Lee, N. A. Patankar, Colloids and Surfaces A: Physicochemical and Engineering Aspects. 248(1-3), 101-104 (2004)

6. D. Enescu, Romanian Biotechnological Letters. 13 (6), 4037-4048 (2008)

7. F. Ferrero, M. Periolatto, Journal of Nanoscience and Nanotechnology 12 (6), 48034810 (2012) DOI: https://doi.org/10.1166/jnn.2012.4902

8. F. L. Zemljič, P. Stenius, J. Laine, K. Stana-Kleinschek, V. Ribitsch, Lenzinger Berichtevol. 85, 68-76 (2006)

9. R. S. Araújo, L. C. Ferreira, Journal of Polymers and the Environment 2018 DOI https://doi.org/10.1007/s10924-018-1270-z

10. M. Roman, WT Winter. Biomacromolecules. 5(5), 1671-1677 (2004)

11. Chih-Ping Chang, Journal of Forest Science 25(3) 231-244 (2010)

12. C. Metzger, S. Sanahuja, L. Behrends, S. Sängerlaub, M. Lindner, H. Briesen Coatings 8(4) 142 (2018) DOI: https://doi.org/10.3390/coatings8040142

13. B. Anwar, B. Bundjali, I.M. Arcana, Procedia Chemistry. 16, 279 - 284( 2015) doi: 10.1016/j.proche.2015.12.051

14. T.S. Gaaz, A.B. Sulong, A.A.H. Kadhum, M.H. Nassir, A.A. Al-Amiery, Materials. 9, 620 (2016) https://doi.org/10.3390/ma9080620

15. I.V. Susoeva, T.N. Vahnina, A. V. Sviridov, Chemistry of vegetable raw materials.3, 211-220 (2017) DOI: 10.14258/jcprm.2017031492 